\title{
PEMANFAATAN KULIT PISANG KEPOK (Musa acuminate L.) SEBAGAI ADSORBEN UNTUK MENURUNKAN KADAR MANGAN PADA AIR SUMUR
}

\author{
Alief Firia Romadhana Hs, Ferry Kriswandana, Darjati
}

\begin{abstract}
ABSTRAK
Air merupakan sumber kehidupan makhluk hidup terutama manusia dengan berbagai macam kebutuhan dasar manusia.Sumber air yang banyak digunakan adalah air tanah yaitu air sumur.Agar memenuhi persyaratan kesehatan perlu dilakukan pengolahan terutama dalam aspek kualitasnya. Air sumur banyak mengandung mineral diantaranya adalah mangan yang apabila konsentarasinya melebihi ambang batas dapat mengganggu kesehatan manusia, oleh karena itu maka diperlukan pengolahan salah satunya dengan proses adsorpsi. Kulit pisang kepok dapat dijadikan sebagai adsorben karena mengandung gugus hidroksil $(-\mathrm{OH})$ dan asam karboksilat yang dapat mengikat ion logam. Penelitian bertujuan untuk mengetahui penurunan kadar mangan dalam air dengan menggunakan kulit pisang kepok (Musa acuminate L.) sebagai bahan adsorben yang dikeringkan. Jenis penelitian ini adalah eksperimen dengan desain penelitia one group pretest-postest design yang membandingkan antara penurunan kadar mangan sebelum dan sesudah proses adsorpsi menggunakan adsorben kulit pisang kepok. Prosentase penurunan kadar mangan setelah dilakukan proses adsorpsi menggunakan adsorben kulit pisang kepok dengan kadar adsorben dan waktu perendaman $10 \mathrm{gr} / \mathrm{l}, 30$ menit; $10 \mathrm{gr} / \mathrm{l}, 60$ menit; $10 \mathrm{gr} / \mathrm{l}, 90$ menit; $20 \mathrm{gr} / \mathrm{l}, 30$ menit; $20 \mathrm{gr} / \mathrm{l}, 60$ menit; $20 \mathrm{gr} / \mathrm{l}, 90$ menit; $30 \mathrm{gr} / \mathrm{l}, 30$ menit; $30 \mathrm{gr} / \mathrm{l}, 60$ menit; $30 \mathrm{gr} / \mathrm{l}, 90$ menit berturut-turut adalah sebesar 17,43\%; 40,40\%; 59,31\%; 23,37\%; 68,61\%; 80,40\%; 47,72\%; 78,12\%; $91,68 \%$. Hasil maksimum penurunan kadar mangan dalam air sebesar $91,68 \%$ untuk kadar adsorben 30gr/l dengan waktu perendaman 90 menit. Pada hasil statistik menghasilkan nilai $\mathrm{P}<0,05$ dengan nilai signifikasi untuk kadar adsorben $\mathrm{P}=0,006$ dan waktu perendaman $\mathrm{P}=0,001$ yang artinya ada pengaruh penggunaan adsorben kulit Pisang Kepok untuk menurunkan kadar mangan (Mn) dalam air sumur dengan kadar adsorben dan waktu perendaman yang berbeda. Hal ini artinya kulit Pisang Kepok dapat digunakan sebagai rancangan proses adsorpsi
\end{abstract}

Kata Kunci : Mangan (Mn), Kulit Pisang Kepok, Adsorben

\section{A. Pendahuluan}

Air merupakan sumber kehidupan makhluk hidup terutama manusia dengan berbagai macam kebutuhan dasar manusia.Air menjadi kebutuhan primer yang diperlukan untuk kebutuhan sehari-hari seperti keperluan untuk masak, mandi, mencuci dan kebutuhan pokok lainnya, sehingga air bersih sangat diperlukan dan harus memenuhi persyaratan, baik kualitas maupun kuantitas.

Sumber air yang banyak digunakan adalah air tanah, yaitu air sumur yang diperlukan manusia untuk kehidupan sehari-hari, oleh karena itu 
pengolahan sumber daya air yang baik sangat penting agar menghasilkan air hasil olahan yang memenuhi persyaratan kesehatan.Ada 3 (tiga) aspek penting yang harus diperhatikan dalam penyediaan air bersih di suatu kawasan, yaitu: aspek kuantitas, kualitas dan kontinuitas.

Peningkatan kualitas air perlu dilakukan dengan mengadakan pengolahan air yang akan digunakan untuk kebutuhan sehari-hari untuk memperoleh air bersih sesuai dengan persyaratan. Menurut Peraturan Menteri Kesehatan Republik Indonesia nomor 32 tahun 2017 Standar Baku Mutu Kesehatan Lingkungan untuk media air keperluan Higiene Sanitasi meliputi parameter fisik, biologi, dan Kimia. Persyaratan kimia ditentukan oleh konsentrasi bahan-bahan kimia seperti Fe, Mn, Cd, Cu, Zn, dll. Menurut Abdur Rahman (2004) menyatakan Air tanah di Indonesia sebagai Negara yang alamnya kaya mineral sering mengandung besi dan mangan yang cukup tinggi.

Masalah yang sering dihadapi adalah kualitas air yang semakin menurun terutama pada air tanah. Seperti halnya yang terjadi di Desa Sepande Candi Kabupaten Sidoarjo, daerah pemukiman warga terjadi penurunan kualitas air tanah yang mengandung kadar mangan (Mn) tinggi. Unsur mangan dalam jumlah kecil diperlukan oleh tubuh manusia dalam metabolismenya. Namun, dalam konsentrasi yang melebihi ambang batas unsur Mangan dapat menyebabkan air berwarna kemerahan, kuning, dan kehitaman, memberi rasa tidak enak pada minuman, menimbulkan noda dalam cucian serta bila teroksidasi akan menimbulkan endapan pada jaringan pipa (Rahmawati, 2009). Selain itu, terhadap kesehatan manusia kadar mangan yang tinggi dapat membahayakan tubuh yaitu dapat mengakibatkan toksisitas pada system syaraf pusat (Widowati, 2008).

Berdasarkan penelitian Istifiarti Mandasari (2016) penurunan kadar mangan dapat dilakukan dengan proses adsorpsi. Dalam penelitiannya mangan dapat diturunkan dengan menggunakan serbuk gergaji kayu kamper sebagai adsorben.Serbuk gergaji kayu memiliki kemampuan sebagai adsorben karena mengandung selulosa. Selain serbuk gergaji kayu,berdasarkan penelitian Jumiati (2015) kulit pisang kepok 
dapat dijadikan adsorben untuk menurunkan kadar besi. Dalam penelitiannya kadar besi dapat diturunkan dengan penurunan tertinggi sebesar $52 \quad \% \quad$ dengan pemeriksaan dilakukan dengan dosis $20 \mathrm{gr}$ dan waktu perendaman selama 60 menit. Adsorben kulit Pisang Kepok juga dapat menurunkan kadar mangan dalam air berdasarkan penelitian yang dilakukan oleh Anny Thuraidah (2015) dengan menggunakan perbedaan kadar adsorben disetiap perlakuannya yang memperoleh hasil dengan kadar tertinggi dapat menurunkan kadar mangan dengan persentase 52,916 \% dengan waktu kontak selama 30 menit. Menurut Hossain (2012) kulit Pisang Kepok dapat mengikat ion logam karena mengandung asam galakturonik yang merupakan fungsi gula karboksil.

Berdasarkan hasil surveypada air sumur gali Desa Sepande Candi Kabupaten Sidoarjo menhasilkan kadar mangan sebesar 1,335 mg/l dimana hal ini melebihi batas maksimal yaitu $0,5 \mathrm{~m} / \mathrm{l}$. Salah satu cara agar air tersebut bisa dijadikan air bersih dan memenuhi persyaratan kesehatan dapat dilakukan dengan pengolahan secara sederhana yaitu adsorpsi menggunakaan kulit Pisang Kepok. Kulit pisang kepok mengandung asam galakturonik yang merupakan gugus fungsi gula karboksil yang dapat mengikat kuat ion logam (Hossain, 2012). Berdasarkan hal tersebut peneliti perlu melakukan penelitian tentang " Pemanfaatan Kulit Pisang Kepok (Musa Acuminate L.) Sebagai Adsorben Untuk Menurunkan Kadar Mangan Pada Air Sumur" dengan tujuan untuk mengetahui kemampuan pengaruh kulit Pisang Kepok sebagai adsorben dalam menurunkan kadar Mn pada air sumur.

\section{B. Metode Penelitian}

Jenis penelitin ini adalah eksperimen, dengan desain penelitian "one group pretest-posttest design" yang membandingkan antara penurunan kadar mangan sebelum dan sesudah proses adsorpsi menggunakan adsorben kulit pisang kepok.

Objek penelitian ini adalah salah satu air sumur di wilayah Desa Sepande Candi Kabupaten Sidoarjo dengan teknik grab sample dan limbah kulit Pisang Kepok Kuning. 
Teknik pengumpulan data dalam penelitian ini diperoleh dari hasil pemeriksaan Laboratorium kandungan Mn pada air sumur dan dengan cara penulusuran literatur-literatur sebagai pelengkap seperti jurnal, skripsi, buku, dll.

Instrumen pada penelitian ini adalah dengan melakukan perlakuan pada air sumur untuk menurunkan kandungan mangan dengan menggunakan kulit Pisang Kepok. Perlakuan yang dimaksud adalah dengan memberikan kulit pisang kepok dengan kadar yang berbeda dan waktu perendaman yang berbeda yaitu dengan proses adsorpsi, dimana kulit Pisang Kepok yang menjadi media adsorben. Perlakuan dilakukan sebanyak 9 perlakuan setiap $1000 \mathrm{ml}$ air sampel diberikan perlakuan yang berbeda. Variasi kadar kulit Pisang Kepok yakni 10 gram; 20 gram; 30 gram yang telah dioven selama 1 jam dimasukkan ke dalam gelas beaker $1000 \mathrm{ml}$ dan dilakukan pengadukan selama 1 menit dengan kecepatan yang sama yaitu 60 rpm kemudian dilakukan perendaman dengan variasi waktu perndaman 30 menit; 60 menit; 90 menit setelah perlakuan tersebut selesai maka dilakukan pemeriksaan laboratorium untuk mengetahui kandungan mangan setelah dilakukan perlakuan.

Analisis yang digunakan yaitu analisi analitik dan deskriptifdengan Uji statistic anova dua arah.

\section{Hasil Penelitian Dan Pembahasan}

Kulit Pisang Kepok dapat digunakan sebagai bahan adsorben dalam proses adsorpsi karena merupakan bahan yang berpori (Moleculer Sieves) yang dapat menyerap ion logam. Selain itu, kulit Pisang Kepok memiliki kandungan yang dapat mengikat ion logam, salah satunya adalah Mn karena mengandung polisakarida yang terdiri dari amilosa, amilopektin, dan selulosa yang nantinya kandungan $\mathrm{Mn}$ dalam air akan terserap pada permukaan adsorben.

Pengolahan dimulai dari pencucian kulit Pisang Kepok menggunakan air bersih yang bertujuan untuk menghilangkan kotoran pada permukaan kulit Pisang Kepok. Setelah itu dilakukan pemotongan kulit Pisang Kepok dengan ukuran yang sama yaitu $3 \times 3$ $\mathrm{cm}$ dengan luas permukaan sebesar $18 \mathrm{~cm}^{2}$ tiap kepingnya, pemotongan 
yang sama dilakukan agar permukaan tiap adsorben mempunyai luas yang sama, karena luas permukaan merupakan salah satu factor yang dapat mempengaruhi adsorpsi. Kulit Pisang Kepok dikeringkan dalam oven dengan suhu $100^{\circ} \mathrm{C}$ selama 1 jam, hal ini dilakukan bertujuan untuk menghilangkan getah pada kulit Pisang kepok dan juga untuk meningkatkan porisitas dinding sel adsorben semakin besar. Dalam pemanasan adsorben juga harus memperhatikan suhu yang digunakan, pemilihan suhu $100^{\circ} \mathrm{C}$ dikarenakan menurut Cavalcante

(2005) pemanasan dengan suhu tinggi yang lebih dari $105^{\circ} \mathrm{C}$ dapat menyebabkan rusaknya adsorben, penyusutan volume, dan penutupan pori-pori adsorben sehingga dapat mengurangi kapasitas adsorpsi terhadap logam yang kemudian kemampuan penyerapannya menurun.

Tabel 1.1

KANDUNGAN KADAR MANGAN SEBELUM DAN SESUDAH PROSES ADSORPSI

\begin{tabular}{|c|c|c|c|c|c|c|c|}
\hline \multirow{3}{*}{ No } & \multirow{3}{*}{$\begin{array}{c}\text { Kadar } \\
\text { Adsorben } \\
(\mathrm{gr} / \mathrm{I})\end{array}$} & \multirow{3}{*}{$\begin{array}{c}\text { Waktu } \\
\text { Perendaman } \\
\text { (menit) }\end{array}$} & \multicolumn{4}{|c|}{ Kadar Mn } & \multirow{3}{*}{$\begin{array}{l}\text { Rata } \\
\text {-rata }\end{array}$} \\
\hline & & & \multirow[b]{2}{*}{$\begin{array}{c}\text { Sebelum } \\
(\mathrm{mg} / \mathrm{I})\end{array}$} & \multicolumn{3}{|c|}{ Sesudah $(\mathrm{mg} / \mathrm{l})$} & \\
\hline & & & & $\begin{array}{c}\text { Replikasi } \\
1\end{array}$ & ${ }_{2}$ Replikasi & $\begin{array}{c}\text { Replikasi } \\
3\end{array}$ & \\
\hline 1. & \multirow{3}{*}{10} & 30 & \multirow{9}{*}{1,010} & 0,810 & 0,888 & 0,805 & 0,834 \\
\hline 2. & & 60 & & 0,612 & 0,605 & 0,590 & 0,602 \\
\hline 3. & & 90 & & 0,412 & 0,418 & 0,402 & 0,411 \\
\hline 4. & \multirow{3}{*}{20} & 30 & & 0,780 & 0,768 & 0,775 & 0,774 \\
\hline 5. & & 60 & & 0,310 & 0,301 & 0,340 & 0,317 \\
\hline 6. & & 90 & & 0,198 & 0,195 & 0,201 & 0,198 \\
\hline 7. & \multirow{3}{*}{30} & 30 & & 0,545 & 0,510 & 0,528 & 0,528 \\
\hline 8. & & 60 & & 0,225 & 0,220 & 0,218 & 0,221 \\
\hline 9. & & 90 & & 0,078 & 0,090 & 0,085 & 0,084 \\
\hline
\end{tabular}

Berdasarkan tabel 1.1 hasil kadar kadar mangan (Mn) dalam air sumur mangan $(\mathrm{Mn})$ stelah prosese yaitu pada kadar adsorben sebesar 30 pengolahan mengalami penurunan gr/l dan waktu perendaman 90 menit artinya nilai kadar mangan lebih kecil yang menghasilkan kadar mangan dari kadar mangan sebelum sebesar $0,084 \mathrm{mg} / \mathrm{l}$ yang artinya telah pengolahan yaitu sebesar $1,010 \mathrm{mg} / \mathrm{l}$. sesuai yang dipersyaratkan yaitu tidak Dalam penelitian ini dari 9 perlakuan yang telah dilakukan terdapat kadar adsorben dan waktu perendaman paling optimum untuk menurunkan melampaui batas maksimal sebesar 0,5 mg/l berdasarkan Permenkes no.32 tahun 2017 tentang Standar Baku Mutu Kesehatan Lingkungan 

ini artinya semakin besar kadar adsorben yang diberikan dan semakin lama waktu perendaman yang digunakan maka semakin besar pula nilai penurunannya.

Kadar Mn yang tinggi akan mengakibatkan dampak bagi kesehatan manusia seperti menurunkan Intelligence Quotiens (IQ) pada anak-anak, insomnia, dan lemah pada kaki. Selain itu, kadar mangan (Mn) yang tinggi dapat menimbulkan kerak kuning pada untuk keperluan Higiene Sanitasi. Hal

kamar mandi dan dapat meninggalkan noda kecoklatan pada pakaian yang dicuci.

Di dalam kuli Pisang Kepok mengandung polisakarida yang terdiri dari amilosa, amilopektin, dan selulosa dimana ketiganya mengandung gugus hidroksil (-OH) dan asam karboksilat yang dapat berinteraksi dengan ion mangan sehingga akan bereaksi dan mengikat logam mangan (Mn) dalam air (Thuraidah, 2015).

Tabel 1.2

PERSENTASE PENURUNAN KADAR MANGAN (MN) SESUDAH PROSES ADSORPSI

\begin{tabular}{|c|c|c|c|c|c|c|}
\hline \multirow[b]{2}{*}{ No } & \multirow{2}{*}{$\begin{array}{c}\text { Kadar } \\
\text { Adsorben } \\
(\mathrm{gr} / \mathrm{I})\end{array}$} & \multirow{2}{*}{$\begin{array}{c}\text { Waktu } \\
\text { Perendama } \\
\text { n (menit) }\end{array}$} & \multicolumn{2}{|c|}{ Kadar Mn } & \multirow{2}{*}{$\begin{array}{c}\text { Nilai } \\
\text { Penurunan } \\
\text { (mg/l) }\end{array}$} & \multirow{2}{*}{$\begin{array}{c}\text { Persentase } \\
\text { Penurunar } \\
(\%)\end{array}$} \\
\hline & & & $\begin{array}{c}\text { Sebelum } \\
(\mathrm{mg} / \mathrm{l})\end{array}$ & $\begin{array}{c}\text { Sesudah } \\
(\mathrm{mg} / \mathrm{l})\end{array}$ & & \\
\hline 1. & & 30 & \multirow{9}{*}{1,010} & 0,834 & 0,176 & 17,43 \\
\hline 2. & 10 & 60 & & 0,602 & 0,408 & 40,40 \\
\hline 3. & & 90 & & 0,411 & 0,599 & 59,31 \\
\hline 4. & & 30 & & 0,774 & 0,236 & 23,37 \\
\hline 5. & 20 & 60 & & 0,317 & 0,693 & 68,61 \\
\hline 6. & & 90 & & 0,198 & 0,812 & 80,40 \\
\hline 7. & & 30 & & 0,528 & 0,482 & 47,72 \\
\hline 8. & 30 & 60 & & 0,221 & 0,789 & 78,12 \\
\hline 9. & & 90 & & 0,084 & 0,926 & 91,68 \\
\hline
\end{tabular}

Berdasarkan tabel 1.2 dapat

diketahui persentase penurunan

(Mn) sebesar 0,084 mg/l dengan nilai penurunan sebesar $0,926 \mathrm{mg} / \mathrm{l}$ dan persentase penurunan mencapai $91,68 \%$ sehingga mencapai batas maksimal yang dipersyaratkan dalam Permenkes no.32 tahun 2018 dimana batas maksimal kadar mangan $(\mathrm{Mn})$ dalam air bersih yaitu $0,5 \mathrm{mg} / \mathrm{l}$.

Hasil statistik dengan menghasilkan nilai $P<0,05$ untuk kadar adsorben menghasilkan nilai $\mathrm{P}$ $=0,006$ dan waktu perendaman menggunakan Uji Two Way Anova 
menghasilkan nilai $P=0,001$ yang artinya ada pengaruh penggunaan adsorben kulit Pisang kepok untuk menurunkan kadar mangan (Mn) dalam air sumur dengan kadar adsorben dan waktu perendaman yang berbeda.

\section{Kesimpulan}

Berdasarkan hasil penelitian dengan penggunaan adsorben kulit Pisang Kepok dalam menurunkan kadar mangan (Mn) pada air sumur di Desa Sepande Candi Kabupaten Sidoarjo adalah sebagai berikut:

1. Kulit Pisang Kepok dapat digunakan sebagai rancangan proses adsorpsi

2. Kandungan mangan (Mn) sampel air sumur di Desa Sepande Candi Kabupaten Sidoarjo sebelum perlakuan sebesar $1,010 \mathrm{mg} / \mathrm{l}$ dan menghasilkan penurunan kadarmangan (Mn) yang berbedabeda pada setiap perlakuan. Penurunan kadar mangan (Mn) tertinggi pada perlakuan kadar adsorben 30 gram dan waktu perendaman 90 menit yaitu sebesar $0,084 \mathrm{mg} / \mathrm{l}$

3. Persentase penurunan kadar mangan $(\mathrm{Mn})$ tertinggi ialah pada adsorben 30 gram dengan waktu perendaman selama 90 menit dengan nilai sebesar 91,68 \%. Penelitian ini dimungkinkan dapat mencapai $100 \%$ dengan menambahkan kadar adsorben dan waktu perendaman

4. Terdapat pengaruh penggunaan adsorben kulit Pisang Kepok dalam menurunkan kadar mangan (Mn) pada air sumur sehingga memenuhi persyaratan dalam Permenkes no.32 tahun 2017 dengan kadar adsorben dan waktu perendaman paling optimum ialah 30 gram dan 90 menit.

\section{E. Saran}

Berdasarkan pembahasan
dalam penelitian ini dapat
disarankan sebagai berikut:

1. Bagi masyarakat diharapkan mampu menjadikan kulit Pisang Kepok sebagai alternatif dalammetode adsorpsi / penyehatan air secara sederhana

2. Bagi peneliti lain yang ingin melanjutkan penelitian sejenis dapat melakukan penurunan kandungan mangan ( $\mathrm{Mn}$ ) dalam air dengan variabel variasi luas permukaan atau variasi pengadukan

3. Bagi peneliti selanjutnya hendaknya meneliti kemungkinan adsorben menjadi busuk terkait waktu perendaman yang digunakan

\section{DAFTAR PUSTAKA}

Anis Rahmawati. 2009. Efisiensi Filter Pasir-Zeolit dan Filter Pasir-Arang Tempurung Kelapa dalam Rangkaian Unit Pengolahan Air untuk Mengurangi Kandungan Mangan dari Dalam Air. Surakarta: Seminar Internasional Hasil Penelitian Eksakta 3

Cavalcante, Costa. Dkk. 2005.Retinal Projections to the midline and intralaminar thalamic nuclei in the common marmoset. Brain Res. 1043,42-47

Hossain dan Nguyen. 2012. Biosorption of $\mathrm{Cu}$ (II) From Water by Banana Peel Based Biosorbent: Experiments and Models of Adsorption and Desorption. Australia: Journal of Water Sustainability. Vol.2, Issue 1

Jumiat,Andi Susilawaty dan Muh.Rusmin. 2015. 
Peningkatan Kualitas Air Sumur

Gali Berdasarkan Parameter Besi )Fe) dengan Pemanfaatan

Kulit Pisang Kepok. Higiene.Vol. 1 , No.1

Mandasari, Istifiarti dan Alfan Purnomo. 2016. Penurunan Ion Besi $(\mathrm{Fe})$ dan Mangan (Mn) dalam Air dengan Serbuk Gergaji Kayu Kamper. Surabaya: Jurnal Teknik. Vol. 5, No. 1

Peraturan Menteri Kesehatan Republik Indonesia Nomor 32 Tahun 2017 Tentang Standar Baku Mutu Kesehatan Lingkungan Dan Persyaratan Kesehatan Air Untuk Keperluan Higiene Sanitasi, Kolam Renang, Solus Per Aqua Dan Pemandian Umum Rahman, Abdur dan Budi Hartono. 2004. Penyaringan Air Tanah Dengan Zeolit Alami Untuk
Menurunkan Kadar Besi dan Mangan. Depok: Makara. Vol. $8, \quad$ No. 1

Syauqiah, Isna, Mayang Amalia dan Hetty A. Kartini. 2011. Analisis Variasi Waktu dan Kecepatan Pengaduk Pada Proses Adsorpsi Limbah Logam Berat Dengan Arang Aktif. Info Teknik. Vo. 12 , No. 1

Thuraidah, Anny. 2015. Kulit Pisang Kepok Untuk Menurunkan Kadar Mangan Air Sumur.

Banjarbaru:MLTJ,ISSN 24610879.http://ejurnalanaliskes.web.id. Vol. No.1 (diakses 3 Januari 2018)

Widowati., Sastiono., Jusuf., 2008. Efek Toksik Logam. Yogyakarta: Pencegahan dan Penanggulangan Pencemaran. Andi Offset 